The PDF of this article has been modified from its original version. 


\title{
Explaining the Great Reversal in Spanish America
}

\author{
Fuzzy-Set Analysis Versus Regression Analysis
}

\author{
AARON KATZ \\ MATTHIAS VOM HAU \\ JAMES MAHONEY \\ Brown University
}

\begin{abstract}
This article evaluates the relative strengths and weaknesses of fuzzy-set analysis and regression analysis for explaining the "great reversal" in Spanish America. From 1750 to 1900, the most marginal colonial territories often became the region's wealthiest countries, whereas the most central colonial territories often became the region's poorest countries. To explain this reversal, five competing hypotheses are tested using both regression and fuzzy-set methods. The fuzzy-set analysis reaches substantively important conclusions, finding that strong liberal factions are probabilistically necessary for economic development and that dense indigenous populations are probabilistically necessary for social underdevelopment. By contrast, the regression analysis generates findings that are not meaningful. The article concludes that fuzzy-set analysis and regression analysis operate in different "causal universes" and that greater attention should be granted to the causal universe occupied by fuzzy-set analysis.
\end{abstract}

Keywords: colonialism; development; necessary causes; sufficient causes

A great reversal occurred in Spanish America during the late colonial epoch. Beginning in the eighteenth century, those colonial territories that had previously been the poorest and most marginal regions of the empire often experienced impressive socioeconomic development, emerging as the wealthiest countries of the region by the twentieth century. Included in this group of successful late-colonial and early-independence developers are Argentina, Costa Rica, and

\footnotetext{
AUTHORS' NOTE: We thank David Collier, Charles C. Ragin, and three anonymous SMR reviewers for their helpful comments. James Mahoney's work on this project is supported by the National Science Foundation under Grant No. 0093754.
} 
Uruguay. By contrast, socioeconomic development stagnated or declined in several of the wealthiest colonial territories during the same time frame. Indeed, by the twentieth century, modern Bolivia, Mexico, and Peru had fallen far from their positions as jewels of the Spanish crown.

This reversal of fortunes merits explanation because the Spanish American countries have tended to maintain their level of development relative to one another since the reversal completed itself by 1900. Thus, once countries such as Argentina and Uruguay had established themselves as regional leaders, they were able to remain in this position without interruption. Similarly, when countries such as Bolivia and Guatemala declined to the bottom of the regional hierarchy, they were unable to recover their former standing (Mahoney 2003). We argue that an explanation of the great reversal in Spanish American history therefore can account for a substantial portion of the variation in levels of development among the contemporary countries of the region.

In this article, we employ both regression methods and fuzzy-set methods as rival tools for explaining the great reversal in Spanish American history. In doing so, we illustrate the quite different ways in which these methodologies think about populations and samples, approach the measurement of variables, and formulate and test causal propositions. $^{1}$

We show concretely how the two techniques differ in their approach to constructing a population of cases for analysis. In regression studies, researchers often work with inclusive definitions of populations-for example, a population of all nation-states - that maximize degrees of freedom but risk introducing unrecognized heterogeneity into the analysis. By contrast, in fuzzy-set studies, researchers often define more delimited populations in which assumptions about unit homogeneity are carefully scrutinized but degrees of freedom are limited. Furthermore, the two approaches differ in their view of cases with extreme values: They are often seen as atypical outliers in regression studies, whereas they are frequently seen as crucial and highly representative instances of a phenomenon in fuzzy-set studies.

We discuss the divergence of the two methods vis-à-vis the measurement of dependent variables (or outcomes, in fuzzy-set analysis) 
and independent variables (or causal factors, in fuzzy-set analysis). Conventional statistical variables are measured on nominal, ordinal, interval or ratio scales. Values on these variables are intended to be objective and they are comprehensible only relative to other possible values on the same variable. By contrast, fuzzy-set analysis requires researchers to measure causal factors and outcomes on a scale of 0 to 1 according to their degree of membership in a given qualitative state. This mode of measurement encourages researchers to infuse causal factors and outcomes with theoretical and substantive knowledge, including by assigning measurement values in ways that reflect specific research goals.

Once populations are selected and variables are operationalized, the two methodologies test hypotheses under different understandings of causal processes. In regression research, analysts often assume linear causation and attempt to estimate the average effect of a given variable net of all other variables. In fuzzy-set research, by contrast, analysts assume necessary and sufficient causation, including combinations of jointly sufficient causes. We show how these differences frame the formulation of distinct research questions and hypotheses, even when researchers believe that the same basic explanatory factors are relevant. Indeed, we conclude that regression methods and fuzzy-set methods cannot test the same hypotheses because the two approaches' contrasting understandings of causation lead them to formulate fundamentally different kinds of hypotheses.

It bears emphasizing that our goal is not to assess the merits and shortcomings of these methodologies across all domains of research. Rather, we evaluate them in light of a particular kind of research design: a comparative-historical analysis that focuses on testing hypotheses for a relatively small number of cases. In this context, we conclude that fuzzy-set methods have important advantages when compared to conventional regression methods.

The article proceeds as follows. We begin with a historical discussion of the great reversal in Spanish American history. Subsequent sections focus on the issues of case selection, hypothesis formulation, variable measurement, and hypothesis testing. In the conclusion, we summarize our findings about Spanish American development and the implications of our argument for methodological practices in the social sciences. 


\section{THE GREAT REVERSAL}

To assess long-run development trajectories in Spanish America, we provide a snapshot of economic and social conditions around 1650, at the height of the colonial period, and compare it to the period after 1900 , by which time nearly all Spanish American countries had achieved independence. In mid-seventeenth-century Spanish America, economic prosperity was largely confined to a few central areas where mineral production was concentrated, especially modern Mexico and Peru. Areas within the productive orbit of these centers, such as regions that correspond approximately to modern Bolivia, Ecuador, Guatemala, and possibly Colombia, also experienced substantial economic activity. However, most territories-including those that make up the modern countries of Argentina, Chile, Costa Rica, El Salvador, Honduras, Nicaragua, Paraguay, Uruguay, and Venezuela-were isolated peripheries of very little economic importance. $^{2}$

During the first 150 years after the Spanish invasion, social conditions were among the worst in human history. The indigenous population-which everywhere still constituted a large majority of the population - suffered a horrific demographic decline, due mostly to warfare and the spread of diseases such as small pox and measles. The percentage of the indigenous population that perished tended to be highest in the more marginal Spanish territories (e.g., Costa Rica) and lowest in the more central territories (e.g., Peru) (Denevan 1992; Newson 1985). These differences in mortality rates were probably linked to the lesser virulence of imported diseases in the highlandsoften the regions with the most concentrated indigenous population (McNeill 1976; Cook and Borah 1971)—and the Spanish elites' need for labor in these areas (Service 1955).

If we compare socioeconomic development during the midseventeenth century to the period around 1900, it is striking to see that the formerly marginal areas were now the most economically and socially developed parts of Spanish America. Thus, Argentina, Uruguay, and Chile became the wealthiest economies in Spanish America; these countries, along with Costa Rica, also displayed the most impressive record for literacy and life expectancy rates in the region. By contrast, Peru, Bolivia, Ecuador, and Mexico were poor 
social performers and, to a lesser degree, poor economic performers. A great reversal had taken place.

The inverse association for levels of colonial development and levels of postcolonial development is not perfect; the correlation coefficient is between -.3 and -.7 , depending on the specific dates and measures used (Mahoney 2003). Nevertheless, this profound turnaround merits systematic explanation. The general forces driving reversal throughout the region were likely related to the gradual weakening of colonial controls and the introduction of free trade and markets in the Spanish colonial empire after the eighteenth century, which allowed the colonial peripheries to capitalize on these opportunities at the expense of the colonial centers (Coatsworth and Taylor 1998). Yet, our goal is to identify the specific features that led some countries to develop and others to suffer decline once the Spanish began to experiment with liberalizing reforms. What was it about the colonial centers that caused them to decline after 1750? What was it about the colonial peripheries that caused them to rise during the same period?

\section{CASE SELECTION}

We begin addressing these questions by consulting both regression and fuzzy-set methodologies for the selection of a population of cases.

CONTRASTING APPROACHES TO CONSTITUTING POPULATIONS

Regression analysis is centrally concerned with achieving adequate degrees of freedom, and therefore often advances inclusive criteria for constituting populations. For example, a cross-national regression study of the effects of colonialism might select all countries that experienced colonial domination (see Bernhard, Reenock, and Nordstrom 2004). This tendency often stands in tension with another important aspect of regression analysis: the assumption of unit homogeneity. ${ }^{3}$ A highly inclusive definition of the population increases the chances that cases will exhibit unrecognized heterogeneity. And when heterogeneous cases are mixed into a single population, the consequence can be misestimating the causal effects of independent variables and overestimating the size of the error vector. 
Fuzzy-set methods begin with the assumption that any large sample of cases likely contains unrecognized heterogeneity, and therefore the burden of justifying a particular population must fall to the analysts themselves. Usually, decisions about the composition of a population are not made definitively until all hypothesized causal factors have been identified and the analysts have assessed how these causal factors could be expected to operate in the broader context of each particular case. A specific case may well be excluded from the population if, based on the contextual features of this case, the researcher concludes that it is impossible to assume that a given causal factor will have the same hypothesized effect in this case as in the rest of the population.

\section{SELECTING A POPULATION OF CASES}

We view an exclusive focus on the former Spanish colonies as consistent with good methodological practices in both fuzzy-set and regression analysis. Although some cross-national studies of the colonial legacy do select a broader range of cases (e.g., Acemoglu, Robinson, and Johnson 2001, 2002), other analysts have found that the effects of colonialism vary depending on the identity of the colonizer (see Bernhard, Reenock, and Nordstrom 2004). For example, whereas level of Spanish colonialism is negatively associated with long-run development, level of British colonialism is positively associated with long-run development (Lange 2003). A model that mixes together Spanish and British colonies thus needs to identify and control for those features of Spain and Britain that produce these opposite effects. Unfortunately, at present, the range of contextual variables that shape the effects of colonialism for different colonizers is not well understood (but see Lange, Mahoney, and vom Hau 2005). Consequently, all analysts face serious problems in conducting an inquiry about the effects of colonialism: limiting the population to, for instance, only Spanish colonies, reduces the available degrees of freedom, whereas including all cases and trying to control for the context of colonialism introduces serious potential model specification problems.

We find it more reasonable to delineate a population of cases that are colonized by the same country and are subjected to the same basic type of colonial rule. This mode of selection helps to control for unknown contextual variables that may substantially shape the effects of colonialism across different colonizers. Fuzzy-set researchers 
normally select cases in this fashion, utilizing their theoretical and empirical knowledge to define a comparable population. We also believe that this case selection approach is the most appropriate choice for regression analysts, who have long worked with a modest number of cases, such as the OECD countries (e.g., Hibbs 1987; Lange and Garrett 1985; and Huber and Stephens 2001). Indeed, these mid- $N$ regression studies fuse expert case knowledge with formal methods of hypothesis testing in ways broadly parallel to fuzzy-set studies.

The Spanish colonized 18 major countries of modern Latin America: Argentina, Bolivia, Chile, Colombia, Costa Rica, Cuba, Dominican Republic, Ecuador, El Salvador, Guatemala, Honduras, Mexico, Nicaragua, Panama, Paraguay, Peru, Uruguay, and Venezuela. From this population, we exclude three countries-Cuba, Dominican Republic, and Panama-for which evidence of interrupted independence processes and multiple colonial experiences leads us to believe that colonialism may not exert an effect on longrun development that is characteristic of the other cases. Cuba did not achieve independence until 1898, and it subsequently came under neocolonial influence from the United States. Panama long was part of Colombia and then also experienced neocolonial influence from the United States. And after independence from Spain, the Dominican Republic was briefly colonized by the French and later recolonized by Spain. Given that these countries did not become independent nations in the same way as the rest of the region, we exclude them on the grounds that we cannot be confident that they meet demands of causal homogeneity.

\section{CONCEPTUALIZING THE DEPENDENT VARIABLES}

In this section, we use fuzzy-set and regression approaches to construct our dependent variables and outcomes: average levels of economic development and social development for the period after which the great reversal had fully completed itself, roughly 1900 to the present.

\section{FUZZY-SET MEASUREMENT}

Dependent variables in fuzzy-set analysis are conceptualized as qualitative states with which cases may vary in their degree 
of membership. Typically, full membership corresponds to what in regression analysis would be seen as an extreme value on a continuous variable. In fuzzy-set analysis, researchers use these cases with extreme values as paradigmatic instances of the phenomenon that they seek to explain.

Here we measure four outcomes as fuzzy-set categories: economically developed country, economically underdeveloped country, socially developed country, and socially underdeveloped country. These measures could be modified by adding an adjective that diminishes or augments the threshold for full conceptual membership, as would occur if one reformulated outcomes as "moderately socially developed country" or "very socially developed country." In turn, these different conceptualizations might substantially change findings by leading to new codes on the outcome variable and perhaps even changing the set of cases that are relevant to the analysis. Likewise, it is worth noting that the categories of economically developed country and economic underdeveloped country are not necessarily mirror images of one another. Rather, it is possible that a case will be a full member of the economically developed country category but not completely outside of the economically underdeveloped country category.

We measure the four outcomes for the period from roughly 1900 to the present. This focus corresponds with the end of the great reversal, which appears to have concluded in most countries by the final decades of the nineteenth century (Mahoney 2003). It is important to note that reliable data for many countries are hard to come by for the early twentieth century.

We code cases according to a seven-value fuzzy set: $1.00,0.83$, $0.67,0.5,0.33,0.17$, and 0.00 . When checked against the historical record, this coding system allows for relatively fine-grained distinctions between cases. We arrive at specific case scores by starting with countries that meet the "qualitative anchors" of full membership (1.00) and full nonmembership (0.00) in a given outcome category. For example, with respect to "economically developed country" in Spanish America, we begin with Argentina, which qualitative and quantitative data suggest is a paradigmatic case for this category. We then identify other countries that can be considered full members of this category (e.g., Uruguay) as well as unambiguous cases of 
nonmembership in the category, such as Honduras. Intermediate cases are evaluated in relationship to the polar extremes.

Our measures are calibrated specifically to the region of Spanish America; they are not intended to gauge all countries of the world. For example, Uruguay's full membership in the category of "socially developed country" reflects this country's position within the region but does not fit a worldwide comparison of social development. Fuzzy-set measurement often works best if it is calibrated to a domain of relatively homogeneous cases such as those of Spanish America.

The first two columns of Table 1 display the fuzzy membership scores of Spanish American countries for the outcomes of economically developed country and economically underdeveloped country. We derived the specific fuzzy-set scores by examining quantitative data on the period from 1900 to 1990 and by considering the qualitative work of case experts. The quantitative data consulted were indices of gross national product (GNP) and gross domestic product (GDP) per capita and automobiles and telephones per capita across the past century. From these data, we developed an ordinal ranking of the countries from most economically developed to least economically developed. We then referred to the case study literature to identify specific cutoff points for the fuzzy-set values.

Columns 4 and 5 of the table report the fuzzy-set scores for socially developed country and socially underdeveloped country. We derived these values in part by examining quantitative data on literacy, education spending, and life expectancy over many or all decades during the past century. These data helped us rank the countries based on their overall social performance from 1900 to 1990. In turn, qualitative studies again suggested specific cutoff points for the fuzzy-set codes.

\section{STATISTICAL MEASUREMENT}

In the regression model, we evaluate two dependent variables: economic development and social development. Both variables are measured continuously on an interval scale. As reported in the third column of Table 1, economic development is operationalized as GDP per capita in 1990, based on three-year averages in U.S. dollars at 1970 prices, as provided by Thorp (1998). The values for 1990 GDP range 


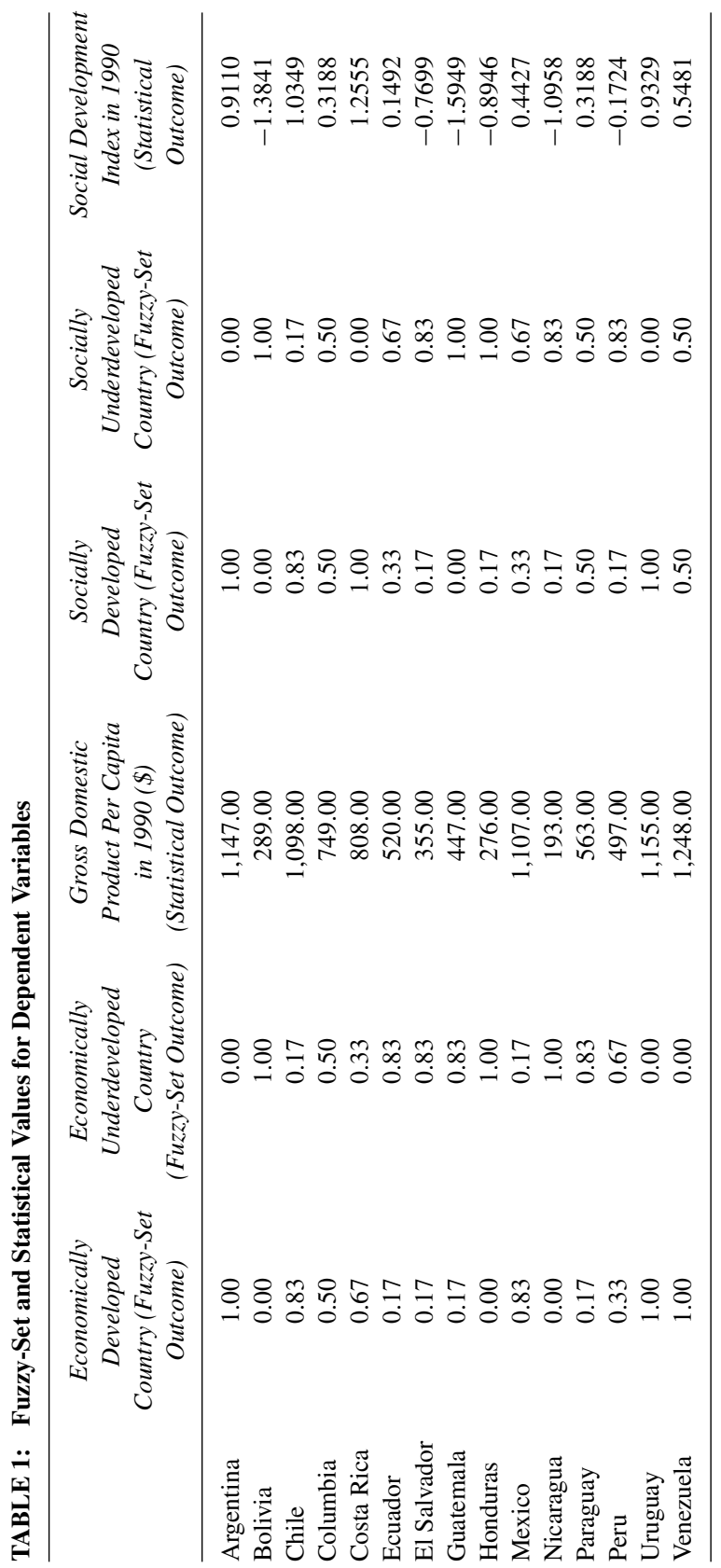


from $\$ 193$ per capita in Nicaragua to $\$ 1,248$ per capita in Venezuela. Mean GDP per capita is $\$ 697$. However, the distribution is relatively polarized; eight countries report GDP per capita below $\$ 600$, while the GDP per capita for five other countries is above $\$ 1,000$.

Thorp's (1998) data include GDP per capita figures for each decade during the 1900 to 1990 period. Our dependent variable, GDP per capita in 1990, was selected because 1990 is the most recent time period in the data set with reliable and complete information for all cases. Before choosing 1990, we examined the correlations between each decade in the period from 1900 to 1990 . The correlation between consecutive decades is, on average, 0.94. The average correlation between all decades and GDP per capita in 1990 is 0.77 , a very strong relationship when one recognizes that data for the poorer countries are often missing in the early twentieth century (e.g., $N=7$ in 1900-1910).

We measure social development using two indicators also found in the Thorp (1998) data set: 1990 literacy rates and 1990 data on life expectancy at birth (LEB). For the purposes of the regression analysis, we created an index of social development combining literacy and LEB. The scores of this index are reported in the last column of Table 1. To construct the index, an average of the standardized $z$ scores for LEB and for literacy was calculated, the mean of the distribution being zero. The range for the combined index of social development is 2.85 standard deviations, with a minimum $z$ score of 1.59 standard deviations below the mean for Guatemala to a maximum of 1.26 standard deviations above the mean for Costa Rica.

We again selected 1990 as the basis for our statistical dependent variable since it is the most recent decade with complete and reliable information for all cases. Our analysis of correlations between consecutive decades indicates that literacy rates, as well as LEB to a lesser extent, are strongly correlated over time. ${ }^{4}$ In addition, we found that the two indicators were themselves highly related, suggesting that they both serve as indicators of the same overarching phenomenon.

The fuzzy-set scores and the statistical values for the dependent variables are compared in Figures 1 and 2. In the first figure for economic development, the thin line represents the GDP per capita values, and the thick line represents the fuzzy-set scores for membership in the set of economically developed countries. The 


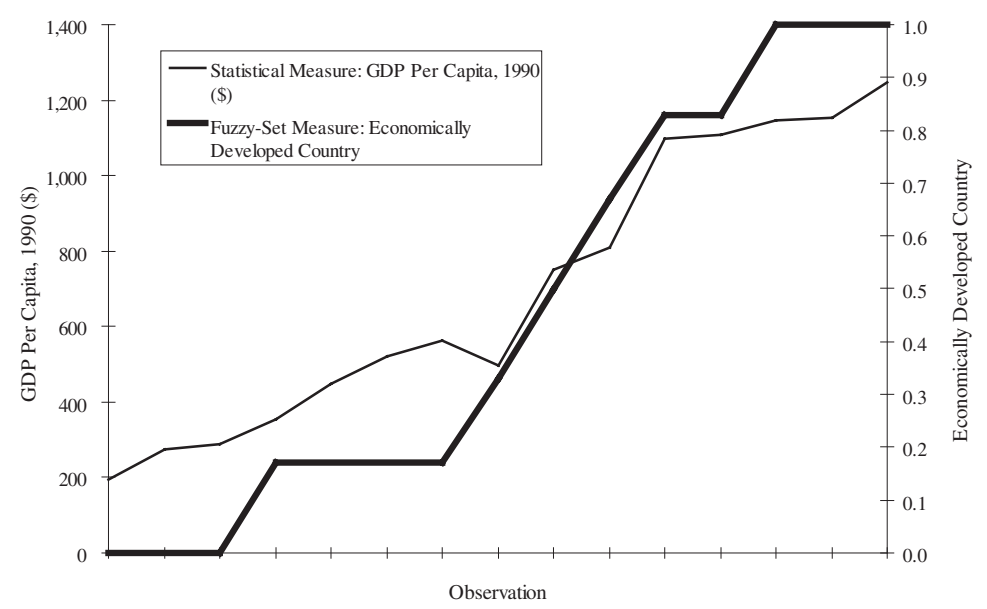

Figure 1: Statistical Versus Fuzzy-Set Measures of Economic Development

correlation between GDP per capita in 1990 and the fuzzy-set scores is 0.98 . The correspondence between the statistical values for social development and fuzzy-set scores for socially developed country is also strong, with a correlation of 0.91 . Hence, while statistical and

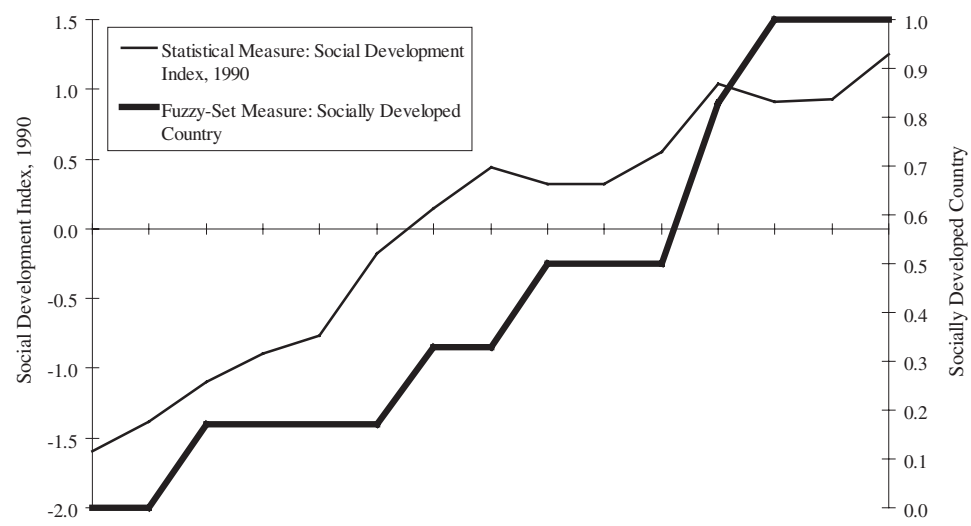

Observation

Figure 2: Statistical Versus Fuzzy-Set Measures of Social Development 
fuzzy-set methods differ considerably in their approaches to conceptualization, we arrive at similar variable scores using the different approaches.

\section{FIVE HYPOTHESES}

This section explores why some countries developed and others stagnated during the process of reversal, much of which took place between 1750 and 1900. In considering potential explanations, we recognize that regression models and fuzzy-set models make different assumptions about the nature of causation, and thus the two techniques formulate different kinds of hypotheses.

Fuzzy-set methods develop hypotheses under the assumption that a given causal factor might be necessary or sufficient for an outcome. With necessary causation, the occurrence of one specific range of values on an outcome variable usually or always requires the presence of one specific range of values on a causal variable. For example, a classic necessary causation hypothesis is the idea that a minimal level of economic development is a prerequisite for democracy. Data are consistent with necessary causation when fuzzy-set scores on the cause are greater than or equal to scores on the outcome. With sufficient causation, one specific range of values on a causal variable will usually or always be associated with one specific range of values on an outcome variable. For example, a sufficient causation hypothesis is the idea that the absence of a minimal level of economic development will almost always produce the absence of democracy. Data are consistent with sufficient causation when fuzzy-set scores on the cause are less than or equal to scores on the outcome.

Necessary and sufficient causation may be premised on either a deterministic or a probabilistic approach. With a deterministic approach, the researcher explores a hypothesis in which a single inconsistent data point is enough to rule out a conclusion of necessary or sufficient causation. With a probabilistic approach, the data may not be fully consistent with necessary or sufficient causation, but the researcher may nevertheless infer that they are consistent with, for example, usually necessary or usually sufficient causation. Here we adopt the probabilistic approach. 
Regression models usually formulate hypotheses under the assumption that a given independent variable might probabilistically increase or decrease values on a dependent variable net of the effect of all other variables. The understanding of causation here is one of linear covariation and ultimately correlation.

\section{THE DENSITY OF THE INDIGENOUS POPULATION}

The first overall hypothesis proposes that the density of the indigenous population accounts for shifting development trajectories in Spanish America. Spanish colonizers usually sought settlement areas with a substantial indigenous population, as in the territories of modern Mexico, Peru, and Bolivia, with the aim of harnessing labor for agriculture and mining. In these areas, the prevalence of colonial exploitation and ethnoracial forms of exclusion might have negatively affected long-run socioeconomic development. By contrast, territories without a dense indigenous population might have displayed less pronounced ethnic divisions, which in turn may have promoted development.

To test these ideas using a fuzzy-set framework, we explore whether "dense indigenous population" and the negation of this condition (i.e., "not dense indigenous population") are probabilistically necessary or sufficient for the four outcomes considered here. The first two hypotheses state that membership in the set of countries with dense indigenous populations will be probabilistically necessary or sufficient for (1) membership in the set of countries that are socially underdeveloped and (2) membership in the set of countries that are economically underdeveloped. Similarly, the third and fourth hypotheses are that membership in the set "not dense indigenous population" will be probabilistically necessary or sufficient for (3) membership in the set "economically developed country" and (4) membership in the set "socially developed country."

Within a regression framework, we hypothesize that the density of the indigenous population is negatively related to indicators of both economic and social development. Therefore, we would expect the coefficient for the variable measuring the density of the indigenous population to be significant and negative. The interpretation of the beta coefficients is that for every one-unit increase on the variable density of the indigenous population, it is probabilistically likely that there 
will be a decrease on the outcome variables, holding other variables constant.

\section{LABOR-INTENSIVE AGRICULTURE}

The historical literature on agrarian structures in Spanish America suggests that large-scale, labor-intensive estates had a negative effect on development (Florescano 1975; Lockhart 1969; Mörner 1973). These estates used semicoercive forms of labor, with the possible consequence of creating a class of impoverished workers that lacked the means for consuming manufactured goods, thereby hindering economic prosperity. In addition, the asymmetrical relationship between hacienda owners and their laborers might have discouraged the implementation of general health and education facilities, undermining social progress. Given that haciendas were common in the central areas of the colonial empire and may have been a less prominent feature in marginal areas, one might argue that these estates can explain the reversal of fortunes.

In the fuzzy-set analysis, therefore, we hypothesize that membership in the set "significant labor-intensive estates" will be (probabilistically) necessary and/or sufficient for membership in the set "economically underdeveloped country" or the set "socially underdeveloped country." Similarly, we expect that membership in the set "not significant labor-intensive estates" will be necessary and/or sufficient for membership in the set "economically developed country" or "socially developed country." In the regression analysis, our hypothesis is that large-scale, labor-intensive agriculture will vary probabilistically and inversely with both social and economic development levels.

\section{TYPE OF EXPORT PRODUCT}

Another research perspective emphasizes the importance of ecological conditions in shaping the type and profitability of agrarian export products in Spanish America. In this approach, the dominance of either tropical agriculture or mineral products in the export economy of a region formed an obstacle to development by providing low return rates in the global economy and preventing domestic investments (Furtado 1976:47-9). In Spanish America during the 
period from 1750 to 1900 , the more central regions may have been especially dependent on mineral exports (e.g., silver and gold) and tropical agricultural exports (e.g., coffee, cacao, and sugar) (BulmerThomas 1994; Coatsworth 1998). By contrast, other areas of the empire may have featured forms of temperate agriculture that could yield higher returns from trade and stimulate domestic investment.

Thus, one may hypothesize in a fuzzy-set analysis that membership in the category of significant mineral exports or in the category of significant tropical export agriculture was necessary and/or sufficient for underdevelopment, whereas the absence of membership in these categories was necessary and/or sufficient for successful development. ${ }^{5}$ Our statistical expectation is a negative probabilistic relationship between levels of tropical agricultural and mineral exports and levels of development.

\section{STRENGTH OF LIBERALS AND CONSERVATIVES}

Finally, we formulate two hypotheses that are based on the argument that areas with a strong capitalist class may have been more likely to achieve socioeconomic development than those regions without such a group of elite actors. The historical literature describes an emerging liberal-conservative cleavage within the colonial elite in the 1750 to 1900 period (Brading 1991; Gootenberg 1996; Mahoney 2001). Precapitalist liberals, as the foremost challengers of colonial rule opposing institutions such as trade monopolies, were predominantly located in the peripheral areas. By contrast, conservative factions, as the core of the colonial elite advocating state regulations and corporate privileges, could be found especially in the central areas of the colonial empire (Halperín Donghi 1993; Knight 2001).

We thus hypothesize in the fuzzy-set analysis that the presence of "strong liberals" was probabilistically necessary and/or sufficient for social and economic development, whereas the presence of "strong conservatives" was probabilistically necessary and/or sufficient for the absence of such development. For the purposes of regression analysis, we hypothesize a positive relationship between the strength of liberals and indicators of development and a negative relationship between the strength of conservatives and indicators of development. 


\section{CONSTRUCTING THE INDEPENDENT VARIABLES}

Some of the hypotheses developed above make reference to explanatory factors that cannot be directly measured using quantitative evidence. For example, the liberal elite strength variable refers to the power of a historical actor for which appropriate numerical data simply cannot be gathered. With such explanatory variables, analysts must make estimates based primarily on qualitative information and their own knowledge of the cases. Fuzzy sets can be helpful in the coding of qualitative variables by forcing analysts to decide the extent to which each case is a member of a given category. Once these fuzzyset values exist, statistical researchers may then decide to use them for their own purposes, perhaps reconceptualizing the measures as ordinal values in a standard regression model.

\section{FUZZY-SET SCORING OF CASES}

Table 2 summarizes the scores for the specific causal factors assessed in the fuzzy-set model. To code cases for the category of dense indigenous population, we relied on three measures of indigenous population for the period around 1800: the absolute number of indigenous persons, indigenous persons per 100 square kilometers, and indigenous persons as a percentage of the total population (Mahoney 2003). To help determine meaningful cutoff points for the fuzzy-set scores, we consulted the work of historians and country experts, who routinely make qualitative observations about the density of the indigenous population. Therefore, the fuzzy-set scores are based not only on numerical information but also on qualitative assessments in prior research.

The scoring of cases for the categories of significant labor-intensive estates, significant tropical export agriculture, and significant mineral exports was based on secondary sources ${ }^{6}$ that report on the economies of the Spanish American countries for the late colonial and early independence periods (approximately 1750-1900). Obviously, the economies of the countries evolved over time. The fuzzy-set scores in Table 2 reflect dominant economic characteristics rather than ephemeral trends.

In scoring cases for membership in the sets "strong liberals" and "strong conservatives," we consulted the substantial literature 
TABLE 2: Fuzzy-Set Scores for Causal Factors

\begin{tabular}{lccccc}
\hline & $\begin{array}{c}\text { Dense Indigenous } \\
\text { Population }\end{array}$ & $\begin{array}{c}\text { Labor-Intensive } \\
\text { Estates }\end{array}$ & $\begin{array}{c}\text { Mineral/Tropical } \\
\text { Exports }\end{array}$ & $\begin{array}{c}\text { Strong } \\
\text { Liberals }\end{array}$ & $\begin{array}{c}\text { Strong } \\
\text { Conservatives }\end{array}$ \\
\hline Argentina & 0.17 & 0.17 & 0.33 & 1.00 & 0.50 \\
Bolivia & 1.00 & 0.83 & 1.00 & 0.17 & 0.67 \\
Chile & 0.33 & 0.83 & 1.00 & 0.83 & 0.50 \\
Colombia & 0.67 & 0.50 & 1.00 & 0.83 & 0.83 \\
Costa Rica & 0.00 & 0.00 & 0.83 & 0.67 & 0.00 \\
Ecuador & 1.00 & 1.00 & 0.50 & 0.33 & 0.67 \\
El Salvador & 0.83 & 0.67 & 1.00 & 0.83 & 0.50 \\
Guatemala & 1.00 & 0.83 & 1.00 & 0.67 & 1.00 \\
Honduras & 0.67 & 0.17 & 0.50 & 0.33 & 0.17 \\
Mexico & 1.00 & 1.00 & 1.00 & 1.00 & 1.00 \\
Nicaragua & 0.83 & 0.33 & 0.33 & 0.67 & 0.67 \\
Paraguay & 0.50 & 0.50 & 1.00 & 0.33 & 0.67 \\
Peru & 1.00 & 1.00 & 1.00 & 0.33 & 1.00 \\
Uruguay & 0.00 & 0.00 & 0.17 & 1.00 & 0.00 \\
Venezuela & 0.50 & 0.33 & 0.33 & 1.00 & 0.33 \\
\hline
\end{tabular}

that views the region in light of a liberal-conservative cleavage. ${ }^{7}$ In comparing cases, we considered the social, political, and economic prominence of those merchant guilds, landlords, and bureaucrats that represented the core of conservative factions. Likewise, we compared those free-market merchants, urban professionals, and intellectuals that made up the core of liberal movements. In many cases, liberalism did not appear on the historical scene until the end of the eighteenth century. Before this time, political factions (often creole merchants and professionals) that opposed colonial restrictions and regulations represented incipient liberals.

\section{QUANTITATIVE SCORING OF CASES}

For the first hypothesis, indigenous population density is operationalized using the three indicators discussed above: absolute size, area density, and size relative to the total population. An index was constructed by creating standardized $z$ scores for each variable and taking the average standardized $z$ score of the three indicators for each country. The highest indigenous population $z$ score (Mexico) is 1.27 standard deviations above the mean, and the lowest (Uruguay) is 1.53 standard deviations below the mean. 
The degree of large-scale, labor-intensive agriculture is measured on an ordinal scale ranging from 1 to 7 , derived from the seven fuzzyset values. Thus, we converted a fuzzy-set score of 0.00 to an ordinal score of 1 , a fuzzy-set score of 0.17 to an ordinal score of 2 , and so on. However, the two kinds of scores must be interpreted differently. The fuzzy-set scores represent degree of membership in a particular qualitative phenomenon; the ordinal scores indicate the rank order of the phenomenon relative to the other cases. We proceeded in the same manner for tropical and mineral export intensity, the presence of strong liberals, and the presence of a strong conservative elite.

Our regression analysis also includes variables to measure the persistence of developmental hierarchies over time. Previous research shows that countries do not generally experience significant mobility within our population of cases; relatively underdeveloped countries tend to stay underdeveloped over time, while more developed countries retain their advantages (Mahoney 2003; see also Acemoglu, Johnson, and Robinson 2001, 2002). For each dependent variable, we ran models that included a lag term for the earliest time period for which data exist for all 15 countries. Accordingly, the lagged dependent variable for GDP per capita is measured as of 1950. Complete data for LEB are only available for 1960 and later decades. Therefore, the lagged index of social development is measured as of 1960.

\section{TESTING THE HYPOTHESES}

In this section, we turn to the task of testing our hypotheses using the two different methods. We once again start with the fuzzy-set analysis.

\section{FUZZY-SET ANALYSIS OF HYPOTHESES}

In our fuzzy-set analysis, we treat a cause or causal combination as "usually necessary" or "usually sufficient" if a proportion of .65 or greater of the cases displays the hypothesized subset relationship between cause and outcome. We test for statistical significance against a null hypothesis that the proportion of cases displaying the relationship is less than .65. We set the significance level at .10, a strict benchmark given the small number of cases. Tables 3 and 4 report 


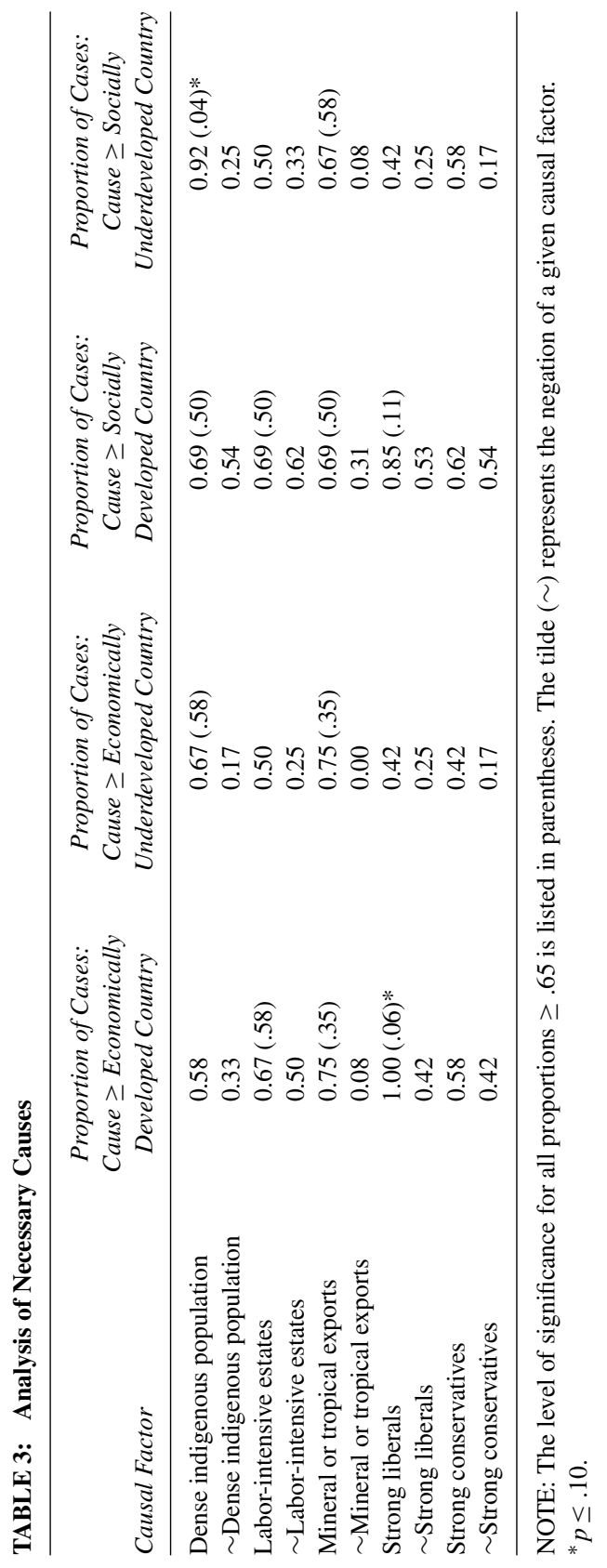




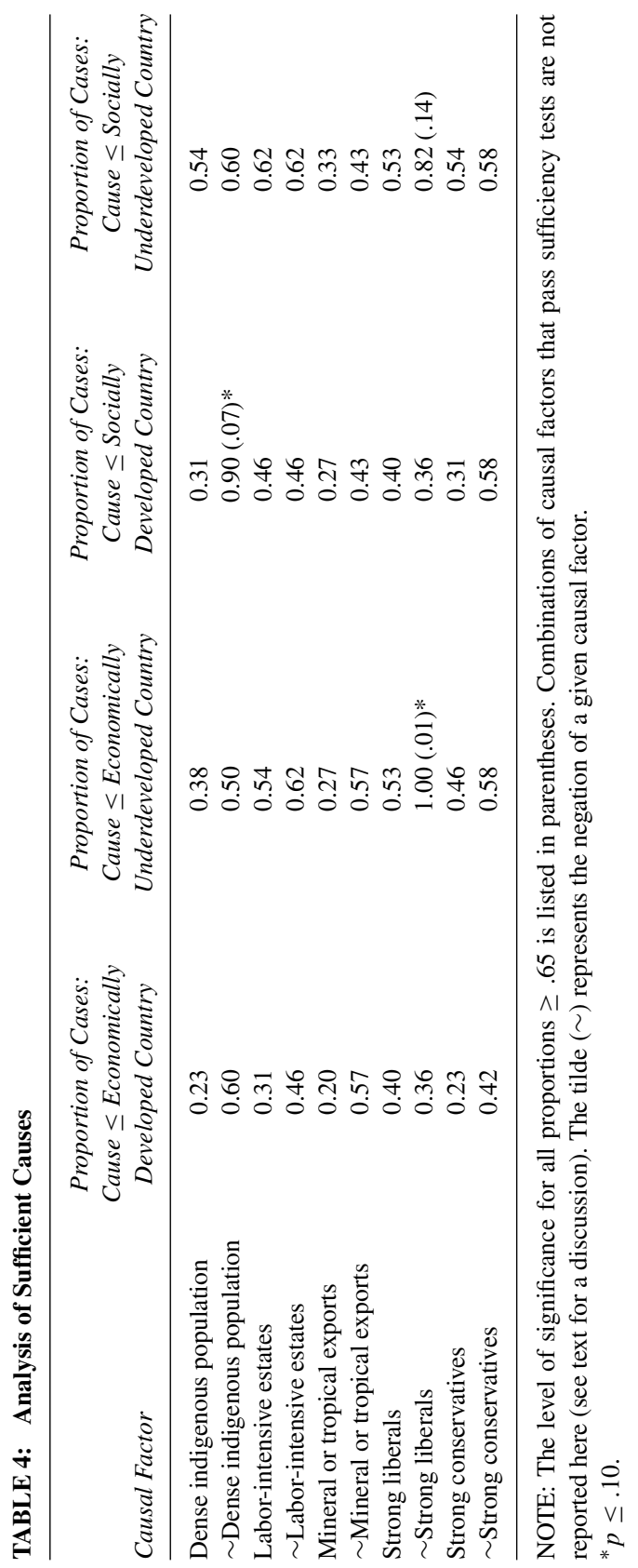


the results for, respectively, usually necessary causation and usually sufficient causation.

The findings produced by fuzzy-set analysis highlight that the density of the indigenous population provides a feasible explanation for the reversal of social development trajectories in Spanish America. The test indicates that membership in the category of dense indigenous population is usually necessary for social underdevelopment; similarly, the absence of a dense indigenous population is usually sufficient for social development. The largest indigenous populations were found in the colonial centers and semiperipheries, enabling the persistence of relatively poor levels of social development in these areas in the period from 1750 to 1900. In addition, the presence of a sparse indigenous population, a more common feature of the colonial periphery, was usually enough for a region to experience a successful shift to a more positive social development trajectory.

The density of the indigenous population does not exhibit causal relevance as a usually necessary or usually sufficient cause with respect to economic development. Rather, our findings indicate that a strong liberal faction was usually necessary for membership in the set "economically developed country." Moreover, the absence of strong liberals proved to be usually sufficient for membership in the set "economically underdeveloped country." Cases featuring relative economic success illustrate these causal patterns. Peripheral regions such as Argentina, Uruguay, or Venezuela, as well as some colonial centers and semiperipheries, especially Mexico and Colombia, all displayed full membership in the strong liberal category. By contrast, regions not achieving successful economic development, such as Bolivia, Ecuador, Honduras, and Paraguay, usually lacked strong liberal factions. Hence, these findings provide a complementary causal story for explaining why colonial centers and semiperipheries with dense indigenous populations sometimes performed a little better with respect to economic development than social development.

The evidence is not consistent with the reverse hypothesis about conservatives. Our data do not support the argument that a strong conservative faction was either usually necessary or usually sufficient for socioeconomic development. This finding resonates well with revisionist histories that de-emphasize the harmful role that conservatives 
play in traditional accounts of development in Spanish America (see Gudmundson and Lindo-Fuentes 1995).

In a similar vein, the propositions concerning labor-intensive estates and mineral/tropical agricultural production do not pass the significance test, either as probabilistically necessary or as probabilistically sufficient causes. A closer look at individual cases shows why. In Chile, large-scale haciendas were present, yet the country still experienced considerable socioeconomic development. Likewise, while Honduras and Nicaragua were not marked by large labor-intensive estates, these countries did not experience substantial development. With respect to minerals and tropical agriculture, we found that almost half of all Spanish American countries displayed significant mineral or tropical agriculture, and these cases included both successful and unsuccessful developers.

Finally, we conducted tests of sufficiency for any logically possible combination of the relevant causal expressions. The results show that two of such combinations passed as usually sufficient for membership in the set of socially underdeveloped country: (1) a dense indigenous population in combination with the absence of large-scale haciendas and (2) a dense indigenous population in combination with the absence of strong liberals. We do not claim to deliver an exhaustive interpretation of these findings. Since we have already seen that a dense indigenous population is usually necessary for social underdevelopment, these results could be seen as highlighting additional factors that make a dense indigenous population both usually necessary and usually sufficient for social underdevelopment. For instance, regions with a relatively extensive indigenous population but with a relative lack of labor-intensive estates, such as Honduras or Nicaragua, appear to have been fully locked into trajectories of underdevelopment.

\section{REGRESSION ANALYSIS OF HYPOTHESES}

Each of our five hypotheses was tested using OLS regression. We started with bivariate regressions of each independent variable on each dependent variable. We then estimated coefficients for models based on different combinations of independent variables (every 
two-variable combination was assessed). Finally, we ran complete regressions incorporating all independent variables.

Table 5 reports simple correlations for all our statistical variables. Table 6 presents the unstandardized OLS regression coefficients for two models; Model 1 includes all our substantive predictors, while Model 2 adds the lagged dependent variable. A glance at Table 5 indicates strong intercorrelations among our predictors, with at least one pair-between labor-intensive agriculture and indigenous population density-demonstrating almost perfect correlation $(r=0.98)$. Overall, we find that most independent variables are also strongly correlated with at least one dependent variable in predicted ways. However, when these variables are assessed side by side in multivariate regressions, the results are difficult or impossible to interpret. We conclude that the statistical tests cannot move beyond making basic claims about bivariate correlations.

The density of the indigenous population is negatively and significantly related to both economic and social development in bivariate models. Once additional variables are included in the model, the size of the effect of indigenous population density becomes highly variable, and the coefficients often are not significant. In fact, the direction of the indigenous population variable actually turns positive in the presence of some variables. Hence, any conclusions based on the coefficient for indigenous population density would be tenuous, at best.

Labor-intensive agriculture is also negatively and significantly correlated with both dependent variables. In the multivariate regression, the coefficient often attains significance, seemingly supporting our hypothesis. However, the size and significance of the coefficient are dependent on the particular model specification. The coefficient for labor-intensive agriculture in a bivariate regression with GDP per capita in 1990 is -101.49 and is significant at the .05 level. With the inclusion of the lagged dependent variable, the coefficient shrinks to an insignificant -18.9 . In the complete model specification, the coefficient on labor-intensive agriculture more than doubles to -209.0 and attains significance at the .10 level.

The intensity of tropical and mineral exports is hypothesized to negatively affect economic and social development. Bivariate regression results do not support this hypothesis, resulting in negative but 


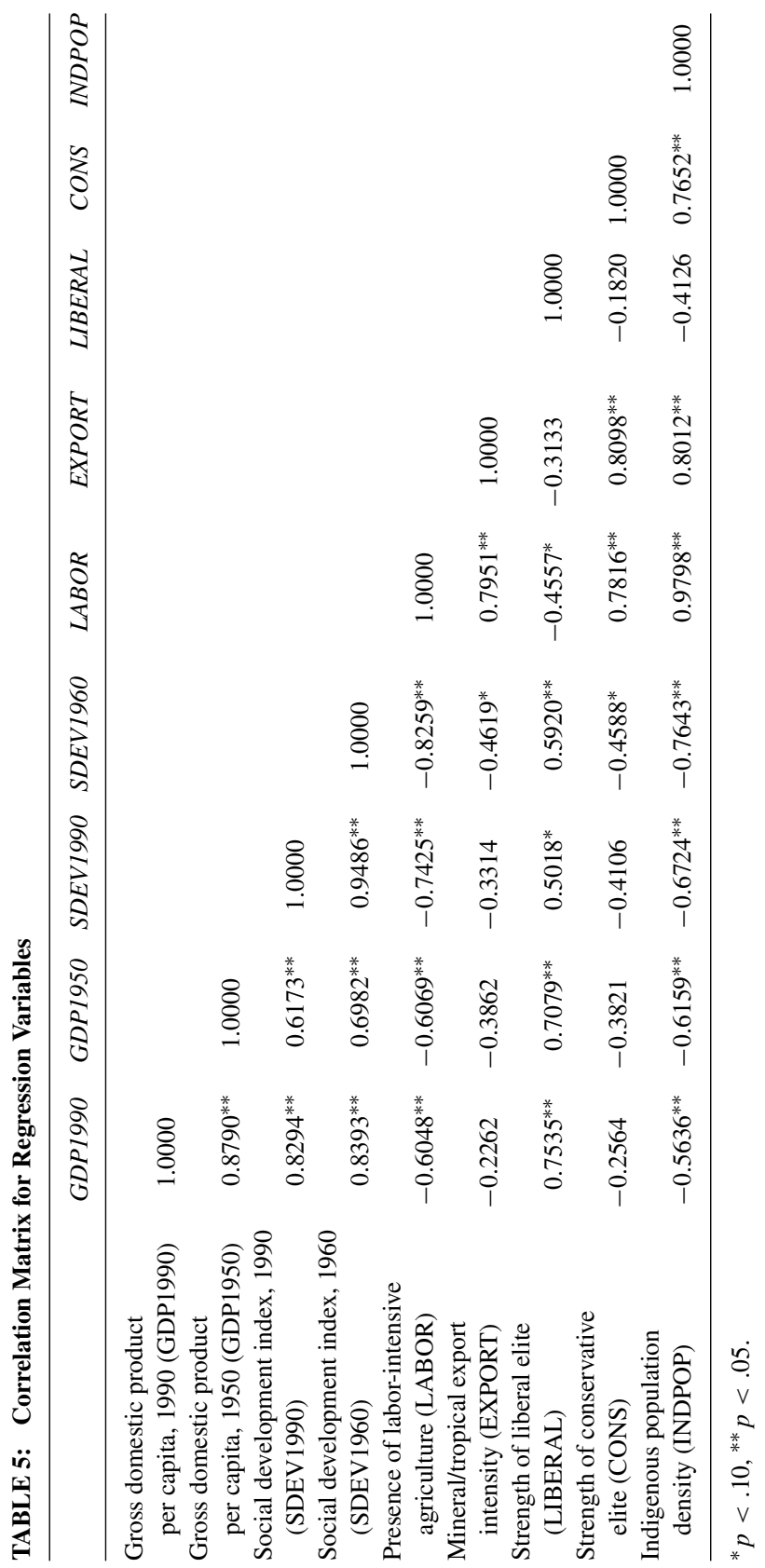


TABLE 6: Unstandardized Coefficients From Regressions of 1990 Gross Domestic Product (GDP) Per Capita on Selected Independent Variables

\begin{tabular}{lcc}
\hline & Model 1 & Model 2 \\
\hline Intercept & 244.686 & 703.878 \\
& $(735.933)$ & $(491.068)$ \\
GDP1950 & & $0.961^{* *}$ \\
& & $(0.261)$ \\
LABOR & -123.708 & $-208.979^{*}$ \\
& $(141.056)$ & $(93.937)$ \\
EXPORT & $105.738^{*}$ & $65.870^{*}$ \\
& $(50.44)$ & $(34.305)$ \\
LIBERAL & $119.113^{* *}$ & 35.811 \\
& $(38.623)$ & $(33.640)$ \\
CONS & -0.182 & 26.230 \\
& $(55.753)$ & $(36.692)$ \\
INDPOP & -41.504 & 276.681 \\
& $(313.888)$ & $(220.209)$ \\
Adjusted $R^{2}$ & 0.678 & 0.866 \\
Number of countries & 15 & 15 \\
\hline
\end{tabular}

NOTE: Numbers in parentheses are standard errors. For definitions of variables, see Table 5 .

${ }^{*} p<.10 .{ }^{* *} p<.05$.

insignificant coefficients. Multivariate regressions provide a different result; the coefficient for tropical and mineral exports attains significance in conjunction with selected independent variables. However, every instance where the coefficient for tropical and mineral exports is significant indicates that tropical/mineral export intensity is positively related to development.

Finally, the variables measuring the strength of liberals and conservatives also demonstrate contradictory results. With respect to both GDP per capita and the social development index, the coefficient for liberal strength is positive and significant in bivariate regression. Interestingly, a bivariate scatterplot of GDP per capita (see Figure 3) against the liberal strength variable is supportive of the idea that liberal strength is a probabilistic necessary cause of economic development, which emerged clearly in the fuzzy-set analysis. The scatterplot has a definite triangular shape, with all cases present in the lower half or very close to the diagonal line bisecting the plot area. The coefficient for strong conservatives is consistently negative for 
TABLE 7: Unstandardized Coefficients From Regressions of 1990 Social Development on Selected Independent Variables

\begin{tabular}{lcc}
\hline & Model 1 & Model 2 \\
\hline Intercept & 2.883 & 0.387 \\
& $(1.864)$ & $(1.333)$ \\
SDEV1960 & & $0.958^{* *}$ \\
& & $(0.248)$ \\
LABOR & $-0.924^{* *}$ & -0.081 \\
& $(0.357)$ & $(0.312)$ \\
EXPORT & $0.245^{*}$ & 0.102 \\
& $(0.128)$ & $(0.088)$ \\
LIBERAL & 0.055 & -0.031 \\
& $(0.098)$ & $(0.065)$ \\
CONS & 0.053 & -0.063 \\
& $(0.141)$ & $(0.093)$ \\
INDPOP & 0.963 & 0.168 \\
& $(0.795)$ & $(0.538)$ \\
Adjusted $R^{2}$ & 0.678 & 0.872 \\
Number of countries & 15 & 15 \\
\hline
\end{tabular}

NOTE: Numbers in parentheses are standard errors. For definitions of variables, see Table 5 .

${ }^{*} p<.10,{ }^{* *} p<.05$.

both dependent variables but does not attain significance in bivariate regression. Therefore, our hypotheses are partially supported in the absence of control variables. In multivariate regression, we again find tremendously unstable coefficient estimates. Depending on the specification of the model, the coefficients fluctuate from positive to negative and attain significance in certain model specifications but not in others. The results for the full-model specification indicate only one significant effect: Liberal strength has a significant $(p=.06)$ positive effect on GDP per capita.

The inclusion of the lagged dependent variable substantially influences the results for both dependent variables. In any of the bivariate models, the lagged dependent variable is consistently significant and tends to mediate any and all effects of the other independent variables. In the complete model with social development as the outcome variable, the inclusion of the lagged dependent variable shifts the coefficients for labor-intensive agriculture and indigenous population density from significance to insignificance. In the complete model 


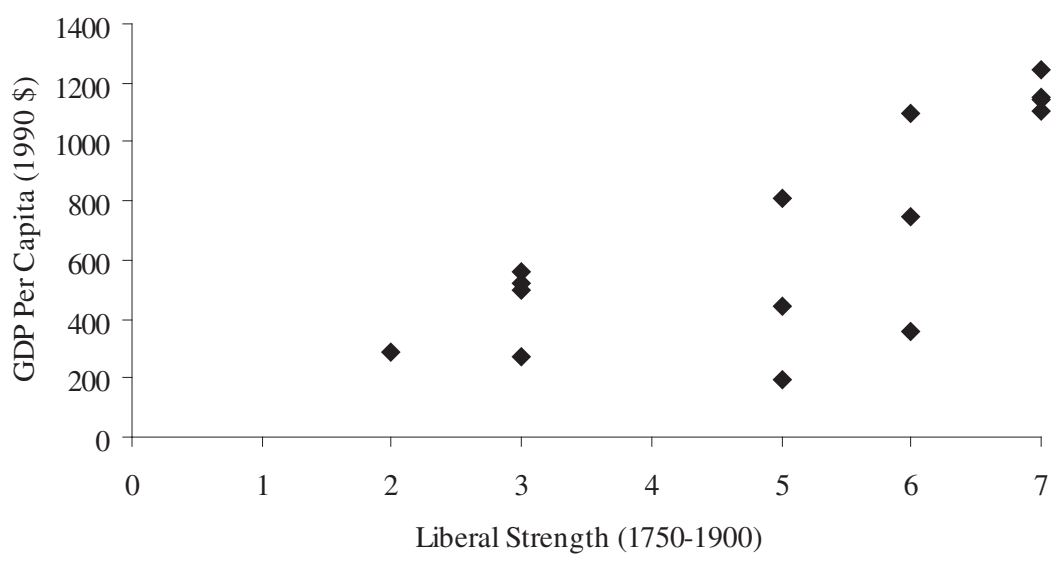

Figure 3: Liberal Strength (1750-1900) Versus Gross Domestic Product (GDP) Per Capita (1990 \$)

specification with GDP per capita as an outcome variable, the lagged dependent variable pushes the coefficient for liberal strength to insignificance while reducing the coefficient on the labor-intensive agriculture variable to marginal significance. Thus, we can draw few conclusions from models incorporating a lag term except to say that a country's past development significantly influences its current level of development.

The coefficients for the lagged dependent variables suggest mixed conclusions about convergence or divergence in levels of social and economic development. With GDP per capita in 1990 as a dependent variable, the coefficient on GDP per capita in 1950 indicates conditional divergence in many multivariate applications. However, in the complete model, the coefficient on GDP per capita in 1950 consistently drops below 1.0, predicting conditional convergence. The inclusion of the lagged dependent variable with literacy rates and life expectancy at birth does not result in a similar quandary. The coefficients for the lagged social development indicator (as of 1960) are consistently less than 1.0, suggesting convergence in social development regardless of model specification. That is, the less socially developed countries have been converging with the more socially developed countries over time. 


\section{DISCUSSION}

We set out to test hypotheses that could explain the great reversal in Spanish American history using both fuzzy-set methods and regression methods. Our fuzzy-set analysis reached substantively meaningful conclusions. In particular, we found that the density of the indigenous population was probabilistically necessary for membership in the category of socially underdeveloped country, while the absence of a dense indigenous population was probabilistically sufficient for socially developed country. Hence, the absence of a dense indigenous population in many colonial peripheries may well explain why they were usually able to reverse themselves for social development from 1750 to 1900, whereas the existence of a dense indigenous population may have generally closed off social development in the colonial centers. We also found that the presence of a strong liberal faction was necessary for membership in the category of economically developed country, whereas the absence of this factor was sufficient for economically underdeveloped country. Thus, the comparatively strong liberal factions of the colonial peripheries may have enabled these formerly marginal areas to take advantage of Spanish free-market reforms after 1750 in a way that was not possible in several of the former colonial centers.

Our regression analysis did not generate meaningful results. The coefficient estimates were unstable, and coefficient variances were high for several variables in almost every multivariate model specification. There are several reasons why the regression analysis produced inconclusive results. First, the small number of cases and, consequently, limited degrees of freedom directly contributed to high variances and lower significance levels. Second, the results from our small sample were highly sensitive to case selection. In fact, we found that the inclusion or exclusion of a single case would sometimes produce radically different coefficient estimates. Third, the high $R^{2}$ and highly significant $F$ statistics in the complete model specification indicated that the models fit the data relatively well. However, the coefficient estimates were unstable and demonstrated high variance. Multicollinearity was a serious problem.

We reassessed the models using options for variance inflation factors (VIF) and eigenvalue analysis. In the complete model 
specification, the VIF for two variables - the extent of labor-intensive agriculture and the density of the indigenous population - are inordinately high. ${ }^{8}$ Eigenvalue analysis provides additional evidence of multicollinearity. ${ }^{9}$ Overall, the instability of the parameter estimates, the relatively large VIF, and the high variance proportions on the coefficients for the extent of labor-intensive agriculture and the density of the indigenous population raise serious concerns. Dropping the density of indigenous population from the model appears to diminish multicollinearity problems without substantially reducing the explanatory power of the model. However, dropping this variable also changes the interpretation of our results since we are no longer controlling for a theoretically important factor.

The fuzzy-set test was less vulnerable to these problems of small$N$, case selection sensitivity, and multicollinearity largely because the hypotheses under consideration involved necessary and sufficient causes. Hypotheses about necessary and sufficient causation are fundamentally bivariate in nature. As Seawright (2002:181) puts it, "the hypothesis entailed in this idea of causation is that no other variable or combination of variables can overcome the effects of the necessary and/or sufficient cause. Therefore, controlling for other variables cannot alter the conclusions of the analysis, and a bivariate focus is fully appropriate." Fuzzy-set analysis is only a multivariate method in the sense that the technique can explore if combinations of variables represent sufficient causes. However, since each combination is reduced to a single value, each combination is, in effect, treated as a single cause. Because of this bivariate orientation, fuzzy-set methods do not suffer from a small- $N$ or degrees of freedom problem equivalent to multivariate regression methods. Rather, with fuzzy-set tests, statistical significance can be reached with a modest number of cases.

Likewise, the role of correlated independent variables is distinct in regression analysis and fuzzy-set analysis. These correlations are the source of multicollinearity in regression analysis, posing major problems for causal inference, especially in the context of a small $N$. By contrast, in fuzzy-set analysis correlations among independent variables simply increase the likelihood that one will reach similar conclusions about the causal relevance of the correlated independent 
variables. For example, if two causal factors are positively correlated, and the analyst discovers that one of them is probabilistically necessary for an outcome, the other causal factor has a higher probability of also being necessary for the outcome than if the causal factors were not correlated. Indeed, in fuzzy-set analysis, it is not unusual to find that two highly correlated causal factors are both necessary (or sufficient) causes. Such findings are in no way logically contradictory, though they do suggest the need for techniques to determine which necessary (or sufficient) cause is more "important" (see Goertz 2004; Mahoney 2005). ${ }^{10}$ In short, then, multicollinearity does not stand in the way of fuzzy-set analysts reaching reliable results about whether causal factors are necessary or sufficient for outcomes of interest.

In closing, we want to emphasize that fuzzy-set techniques are not appropriate for all research questions. For many research topics, one will do best with regression techniques. This is especially true for large- $N$ studies in which one's concern is more with the "effects of a cause" and less with the "causes of an effect." Indeed, as the number of cases increases, one will typically become more concerned with estimating average net causal effects for a class of events and less with identifying the factors that produce specific events (Goertz and Starr 2002). As this takes place, regression methods will often serve better than fuzzy-set methods. For example, if one's goal is to estimate the average effect of labor-intensive agriculture on development for a large number of cases, mainstream statistical techniques generally will be more appropriate. By contrast, if one's goal is to explain differing levels of development in a specific group of cases, fuzzy-set analysis will often work better.

This discussion reinforces the idea that regression approaches and fuzzy-set approaches are predicated on different basic underlying assumptions about causality, or what has been called different "causal universes" (Goertz and Starr 2002). Many or most scholars are unaware of these alternative causal universes and their implications for social science analysis. Largely, this is due to the fact that linearstatistical approaches dominate methodological practices in the social sciences. This article suggests the drawbacks of such dominance for one substantive research question about development trajectories in Spanish America. 


\section{NOTES}

1. Our discussion of fuzzy-set analysis draws extensively on Ragin's (2000) book. In our section on "case selection," we rely on his chapter 7, especially pp. 50-53; in our discussion of fuzzy-set measurement, we rely heavily on chapter 6 , especially pp. 160-71; our probabilistic test of necessary causes follows chapter 8; and our probabilistic test of sufficient causes follows chapter 9 .

2. This section draws on the following works for basic historical details on Latin America: Burkholder and Johnson (1998), Lockhart and Schwartz (1983), and Halperín Donghi (1993).

3. Unit homogeneity means that the unmeasured characteristics of the cases are normally and independently distributed with a mean of zero and a common variance of sigma-squared. When these conditions hold, the net causal effect of a given change on an independent variable will be constant across all cases in the population. King, Keohane, and Verba (1994:91-94).

4. Literacy rates are very highly correlated ( 0.99 on average) over time. Furthermore, literacy rates in earlier decades are highly correlated with literacy rates in 1990 ( 0.86 on average). Life expectancy at birth (LEB) demonstrates a similarly high average decade-over-decade correlation of 0.95. However, the average correlation between LEB in the decades from 1900 to 1980 and LEB in 1990 is lower (0.69).

5. Here we explore the combination of two causal factors - significant mineral exports or significant tropical export agriculture. For a discussion of the use of the logical "or" with fuzzy sets, see Ragin (2000:174-6).

6. Among the major historical works we consulted were Bulmer-Thomas (1994), Coatsworth and Taylor (1998), García and Daniel (1993), and MacLeod (1973).

7. The scores for these two fuzzy-sets rely, among others, on Gootenberg (1996), Guardino and Walker (1992), Gudmundson and Lindo-Fuentes (1995), Halperín Donghi (1988), López Alves (2000), Lynch (1986), and Mahoney (2001).

8. Unfortunately, this is only an approximate indication of collinear variables. There is no consensus as to how high a variance inflation factor (VIF) must be to decisively classify variables as collinear; we can only consider the size of the VIF relative to the VIF for other variables.

9. Here we follow Belsley, Kuh, and Welsch (1980) and Freund, Littell, and SAS Institute (1991), who suggest using a two-step test. First, we pick eigenvectors with condition numbers greater than or equal to 30 . Small eigenvalues, which are associated with high condition numbers, are an indication of near-linear dependencies or extensive multicollinearity. Second, we identify potentially collinear variables as those whose variance proportions are greater than 0.50 . In this second step, we are effectively singling out the variables that may be involved in a collinear relationship that are associated with a suspect eigenvector. Neither eigenvalue analysis of GDP per capita in 1990 nor of the social development index suggests a particularly serious problem of multicollinearity. The highest condition numbers are 16.2 for the economic development and 20.0 for social development.

10. Goertz (2004) develops techniques for assessing empirically the extent to which necessary and sufficient causes are "trivial" and "relevant." Mahoney (2005) explores the ways in which bivariate necessary causation relationships can be elaborated and tested through the introduction of third variables. He suggests that some necessary causes may be considered spurious in light of third antecedent variables. 


\section{REFERENCES}

Acemoglu, Daron, Simon Johnson, and James A. Robinson. 2001. "The Colonial Origins of Comparative Development: An Empirical Investigation." American Economic Review 91:1369-1401.

2002. "Reversal of Fortune: Geography and Institutions in the Making of the Modern World Income Distribution.” Quarterly Journal of Economics 117:1231-94.

Belsley, David A., Edwin Kuh, and Roy E. Welsch. 1980. Regression Diagnostics: Identifying Influential Data and Sources of Collinearity. New York: John Wiley.

Bernhard, Michael, Christopher Reenock, and Timothy Nordstrom. 2004. "The Legacy of Western Overseas Colonialism on Democratic Survival." International Studies Quarterly 48:225-250.

Brading, David A. 1991. The First America: The Spanish Monarchy, Creole Patriots, and the Liberal State, 1492-1867. Cambridge, UK: Cambridge University Press.

Brady, Henry and David Collier, eds. 2004. Rethinking Social Inquiry: Diverse Tools, Shared Standards. Lanham, MD: Rowman \& Littlefield.

Bulmer-Thomas, Victor. 1994. The Economic History of Latin America Since Independence. Cambridge, UK: Cambridge University Press.

Burkholder, Mark A. and Lyman L. Johnson. 1998. Colonial Latin America. New York: Oxford University Press.

Coatsworth, John H. 1998. "Economic and Institutional Trajectories in Nineteenth-Century Latin America." Pp. 23-54 in Latin American and the World Economy Since 1800, edited by John H. Coatsworth and Alan M. Taylor. Cambridge, MA: David Rockefeller Center for Latin America Studies, Harvard University.

Coatsworth, John H. and Alan M. Taylor, eds. 1998. Latin American and the World Economy Since 1800. Cambridge, MA: David Rockefeller Center for Latin America Studies, Harvard University.

Cook, Sherburne F. and Woodrow Borah. 1971. Essays in Population History: Mexico and the Caribbean. Berkeley: University of California Press.

Denevan, William M. 1992. "Native American Populations in 1492: Recent Research and a Revised Hemispheric Estimate." Pp. xvii-xxix in The Native Population of the Americas, edited by William M. Denevan. Madison: University of Wisconsin Press.

Florescano, Enrique. 1975. Haciendas, latifundios y plantaciones en América Latina. Mexico: Siglo Veintiuno Editores.

Freund, Rudolf Jakob, Ramon C. Littell, and SAS Institute. 1991. SAS System for Regression. Cary, NC: SAS Institute.

Furtado, Celso. 1976. Economic Development of Latin America: Historical Background and Contemporary Problems. Cambridge, UK: Cambridge University Press.

García, S. and D. Daniel. 1993. "Economic Growth and Stagnation in the Colonial Americas: An Exploratory Essay." Pp. 51-87 in Development and Underdevelopment in America: Contrasts of Economic Growth in North and Latin America in Historical Perspective, edited by Walther L. Bernecker and Hans Werner Tobler. Berlin: Walter de Gruyter.

Goertz, Gary. 2002. "Cause, Correlation, and Necessary Conditions." Pp. 47-64 in Necessary Conditions: Theory, Methodology, and Application, edited by Gary Goertz and Harvey Starr. New York: Rowman \& Littlefield.

Goertz, Gary. 2004. "Assessing the Importance of Necessary and Sufficient Conditions in Fuzzy-Set Social Science." Manuscript, Department of Political Science, University of Arizona. 
Goertz, Gary and Harvey Starr, eds. 2002. Necessary Conditions: Theory, Methodology, and Applications. New York: Rowman \& Littlefield.

Gootenberg, Paul. 1996. "Paying for Caudillos: The Politics of Emergency Finance in Peru, 1820-1845." In Liberals, Politics and Power: State Formation in Nineteenth-Century Latin America, edited by Vincent C. Peloso and Barbara A. Tenenbaum. Athens: University of Georgia Press.

Guardino, Peter and Charles Walker. 1992. "The State, Society, and Politics in Peru and Mexico in the Late Colonial and Early Republican Periods." Latin American Perspectives 19:10-43.

Gudmundson, Lowell and Héctor Lindo-Fuentes. 1995. Central America, 1821-1871: Liberalism Before Liberal Reform. Tuscaloosa: University of Alabama Press.

Halperín Donghi, Tulio. 1988. “Argentina: Liberalism in a Country Born Liberal.” Pp. 99-116 in Guiding the Invisible Hand: Economic Liberalism and the State in Latin American History, edited by Joseph L. Love and Nils Jacobsen. New York: Praeger.

. 1993. The Contemporary History of Latin America. Durham, NC: Duke University Press.

Hibbs, Douglas A. 1987. "On the Political Economy of Long-Run Trends in Strike Activity." In Hibbs, The Political Economy of Industrial Democracies. Cambridge, Mass.: Harvard University Press.

Huber, Evelyne, and John D. Stephens. 2001. Development and Crisis of the Welfare State: Parties and Policies in Global Markets. Chicago: University of Chicago Press.

King, Gary, Robert O. Keohane, and Sidney Verba. 1994. Designing Social Inquiry: Scientific Inference in Qualitative Research. Princeton, NJ: Princeton University Press.

Knight, Alan. 2001. "Democratic and Revolutionary Traditions in Latin America." Bulletin of Latin American Research 20:147-86.

Lange, Matthew. 2004. "The British Colonial Lineages of Despotism and Development." Ph.D. dissertation, Department of Sociology, Brown University.

Lange, Matthew, James Mahoney, and Matthias vom Hau. 2005. "Colonialism and Development: A Comparative Analysis of Spanish and British Colonies." American Journal of Sociology, forthcoming.

Lange, Peter and Geoffrey Garrett. 1985. "The Politics of Growth: Strategic Interaction and Economic Performance in Advanced Industrial Democracies, 1974-1980." Journal of Politics 47:792-827.

Lockhart, James. 1969. "Encomienda and Hacienda: The Evolution of the Great Estate in the Spanish Indies." Hispanic American Historical Review 49:411-29.

Lockhart, James, and Stuart B. Schwartz. 1983. Early Latin America: A History of Colonial Spanish America and Brazil. Cambridge, UK: Cambridge University Press.

López Alves, Fernando. 2000. State Formation and Democracy in Latin America, 1810-1900. Durham, NC: Duke University Press.

Lynch, John. 1986. The Spanish American Revolutions, 1808-1826. New York: Norton.

MacLeod, Murdo J. 1973. Spanish Central America: A Socioeconomic History, 1520-1720. Berkeley: University of California Press.

Mahoney, James. 2001. The Legacies of Liberalism: Path Dependence and Political Regimes in Central America. Baltimore: Johns Hopkins University Press.

—. 2003. "Long-Run Development and the Legacy of Colonialism in Spanish America." American Journal of Sociology 109:51-106.

—. 2005. "The Elaboration Model: Necessary Causes, and the Explanation of Particular Events." In Causal Explanations, Necessary Conditions, and Case Studies: World War I and the End of the Cold War, edited by Gary Goertz and Jack S. Levy. Under Review.

McNeill, William H. 1976. Plagues and People. New York: Anchor. 
Mörner, Magnus. 1973. "The Spanish American Hacienda: A Survey of Recent Research and Debate." Hispanic American Historical Review 53:183-216.

Newson, Linda A. 1985. "Indian Population Patterns in Colonial Spanish America." Latin American Research Review 20:41-74.

Ragin, Charles C. 2000. Fuzzy-Set Social Science. Chicago: University of Chicago Press.

Seawright, Jason. 2002. "Testing for Necessary and/or Sufficient Causation: Which Cases Are Relevant?" Political Analysis 10:178-93.

Service, E. R. 1955. "Indian-European Relations in Colonial Latin America." American Anthropologist 57:411-25.

Thorp, Rosemary. 1998. Progress, Poverty, and Exclusion: An Economic History of Latin America in the 20th Century. New York: Inter-American Development Bank.

Aaron Katz is a Ph.D. student in the Department of Sociology at Brown University. His dissertation research is on industrial development and the globalization of high-tech industry. It is a study of the integration of firms from follower countries into global value chains in the software industry. His research interests are globalization, economic development, and social networks.

Matthias vom Hau is a Ph.D. student in the Department of Sociology at Brown University. He is currently completing his dissertation, a comparative-historical analysis of why nationalism radically changed in twentieth-century Argentina, Mexico, and Peru. His research interests center on collective identities, state formation, and development.

James Mahoney is an associate professor of sociology at Brown University. He is the author of The Legacies of Liberalism: Path Dependence and Political Regimes in Central America (2001), which received the Barrington Moore Jr. Prize of the Comparative and Historical Sociology Section of the American Sociological Association. He is now beginning a new book project, tentatively titled Colonialism and Development: Spanish America in Comparative Perspective. 